\title{
INFORMAÇÃO E SENSACIONALISMO NO JORNALISMO DE REVISTA: ANÁLISE DA CO- BERTURA DA TRAGÉDIA DA BOATE KISS
}

CLÁUDIA DE OLIVEIRA MENDES UNIVERSIDADE FEDERAL DE MINAS GERAIS BELO HORIZONTE, MINAS GERAIS, BRASIL CLAUDIAMENDES2@LIVE.COM

LUCIANA AMORMINO CENTRO UNIVERSITÁRIO - UNA BELO HORIZONTE, MG, BRASIL E-MAIL: LUAMORMINO@GMAIL.COM 


\section{INFORMAÇÃO E SENSACIONALISMO NO JORNALISMO DE REVISTA: ANÁLISE DA COBERTURA DA TRAGÉDIA DA BOATE KISS}

Resumo: Neste artigo, propõe-se compreender os limites entre informação e sensacionalismo na apuração jornalística de um acontecimento, a partir da cobertura do incêndio ocorrido na boate Kiss (Santa Maria, RS), pelas revistas IstoÉ e Veja, em suas edições especiais de 06 de fevereiro de 2013. Após análise, pôde-se observar que o conceito de jornalismo com informação e sensacionalismo foi praticado pelas revistas analisadas no período supracitado.

Palavras-chave: Jornalismo; Revista; Notícia; Sensacionalismo

\section{INFORMACIÓN Y SENSACIONALISMO EN EL PERIODISMO ESCRITO EN REVISTA: ANÁLISIS DE LA COBERTURA DE LA TRAGEDIA DE LA DISCOTECA KISS}

Resumen: En este artículo científico, se propone comprender los límites entre información y sensacionalismo en la investigación periodística de un acontecimiento, a partir de la cobertura del incendio ocurrido en la discoteca Kiss (Sana Maria, RS), por las revistas IstoÉ y Veja, en sus ediciones especiales del 06 de febrero de 2013. Después de análisis, se pudo observar que el concepto de periodismo con información y sensacionalismo fue practicado por las revistas analizadas en el período sobredicho.

Palabras clave: Periodismo; Revista; Noticia; Sensacionalismo

\section{INFORMATION AND SENSATIONALISM IN MAGAZINE JOURNALISM: AN ANALYZES OF THE COVERING OF THE BURNING IN THE KISS NIGHTCLUB}

Abstract: In this paper it is aimed to comprehend the limits between informative and sensationalistic news of the journalistic reckon of a fact by the covering of the burning occurred in the Kiss Nightclub (Santa Maria, RS) made by IstoÉ and Veja magazines in its special editions of 2013 February 6th. After analyzing the journalistic reckon, it is possible to perceive that both magazines practiced the concept of journalism that brings informative and sensationalistic news on that specific period.

Keywords: Journalism; Magazine; News; Sensationalism 


\section{INTRODUÇÃO}

O avanço da tecnologia nos meios de comunicação alterou o processo de produção da notícia e proporcionou à sociedade o acesso a esta com mais facilidade e frequência, dada a veiculação por meio da internet. Em uma busca simples, é possível obter a informação em tempo real e, também, resgatar fatos passados. Diante disso, houve, e há constante, necessidade de a mídia impressa se readequar, buscando formas de "prender" o leitor.

O jornalismo de revista tem como característica um texto instigante e sedutor, com a combinação entre técnicas jornalísticas e literárias. Segundo Villas Boas (1996, p. 9), "as revistas fazem jornalismo daquilo que ainda está em evidência nos noticiários, somando a estes, pesquisa, documentação e riqueza textual". Observa-se nas reportagens de revista textos em profundidade, com uma abordagem mais ampla, além dos recursos gráficos e de imagens que possibilitam ao leitor uma visão abrangente do universo da notícia.

Marcondes Filho (1988 apud PENA, 2010) afirma que o jornalismo se relaciona com a manutenção do capitalismo, por isso a notícia é um produto. Assim, o tratamento dado à notícia muitas vezes apresenta características do sensacionalismo com a intenção de atrair o leitor, seja comovendo-o, seja chocando-o, seja sensibilizando-o.

O dia 27 de janeiro de 2013 ficou marcado na história do Brasil pelo incêndio ocorrido na casa de shows Kiss, na cidade de Santa Maria, no Rio Grande do Sul. Houve grande repercussão nas imprensas nacional e internacional, com status de tragédia, devido às circunstâncias e ao impacto causado.

Conforme noticiado à época, por volta das 2 h30 da madrugada, um sinalizador aceso por um dos integrantes da banda Gurizada Fandangueira provocou um incêndio que resultou na morte de 242 pessoas e deixou outras 116 feridas. A temperatura dentro da boate no momento do incêndio chegou a $300^{\circ} \mathrm{C}$, mas a causa da morte no local da maioria das 235 vítimas foi intoxicação com a fumaça. As demais mortes ocorreram com o tempo, após

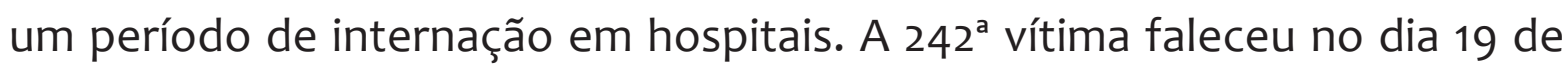
maio do mesmo ano.

Principais revistas semanais de grande circulação no país, IstoÉ e Veja publicaram, respectivamente, reportagem e edição especiais para cobertura do acontecimento.

Este artigo visa à compreensão dos limites entre informação e sensacio- 
nalismo, bem como o posicionamento das revistas IstoÉ e Veja, a partir da análise da cobertura jornalística do incêndio da boate Kiss nas edições publicadas em 06 de fevereiro de 2013. Utilizou-se a metodologia qualitativa, de acordo com Minayo (2009), que permitiu comparações e interpretações, tendo como base para estas conceitos e características do jornalismo, especificamente jornalismo de revista. Dessa forma, foi possível estabelecer uma base para a discussão acerca dos elementos que caracterizam uma linguagem como sensacionalista no jornalismo informativo.

\section{NOTICIABILIDADE}

A célebre frase de Amus Cummings ${ }^{1}$ é considerada uma fórmula básica no conceito de notícia: "Se um cachorro morde um homem, não é notícia; mas se um homem morde um cachorro, aí, então é notícia, e sensacional". Pode-se entender com essa afirmação que notícia é aquilo que rompe com o cotidiano, neste caso, inverte a lógica dos acontecimentos e, assim, desperta o interesse público.

A noticiabilidade é um conjunto de elementos pelo qual os meios de comunicação selecionam os acontecimentos que são notícia, conforme Traquina (2005). Para o autor, a noticiabilidade detém critérios e operações que possibilitam um tratamento jornalístico do fato, ou seja, possui valor como notícia. Já para Wolf (2003), esses critérios determinam os acontecimentos que podem ser noticiados, a estes o autor denomina de "valores-notícia", um componente da noticiabilidade.

Galtung e Ruge (1965) foram os primeiros autores a estudarem os critérios de noticiabilidade e, conforme Traquina (2005), determinaram doze fatores que respondem à pergunta de como um acontecimento pode se transformar em notícia, sendo eles: frequência/duração do acontecimento, amplitude do evento, clareza ou falta de ambiguidade, significância, consonância (facilidade de inserir o 'novo' numa velha ideia que corresponda ao que se espera que aconteça), inesperado, continuidade (continuação daquilo que já ganhou noticiabilidade), composição (a necessidade de manter um

$1 \quad$ O jornalista norte-americano Amus Cummings, ex-editor do jornal The New York Sun, é considerado um dos principais representantes do chamado novo jornalismo nos anos 30, séc. XIX. Disponível em: <http://danielledenny.blogspot.com.br/2012/06/fichamento-do-livro-narracao-do-fato-de.html>. Acesso em: 24 fev. 2014. 
equilíbrio nas notícias, diversificando os assuntos abordados), referências a nações de elite, proeminência, personalização (referindo-se às pessoas envolvidas), negatividade (referindo-se à expressão Bad News is Good News; "más notícias são boas notícias", em tradução livre).

Em uma lista mais recente, Erbolato (2006) ainda acrescenta outros critérios de valor-notícia, como: humor, progresso, sexo e idade, interesse pessoal e humano, rivalidade, utilidade, oportunidade, dinheiro, expectativa ou suspense, originalidade, culto de heróis, descobertas e invenções, repercussão (de caso) e confidências (fofocas).

\section{JORNALISMO DE REVISTA}

Devido à sua periodicidade - semanal, quinzenal ou mensal -, as revistas têm funções mais complexas. Não se trata apenas da transmissão de notícias, mas também entretenimento, análise, reflexão, concentração e experiência de leitura. Segundo Villas Boas (1996), por causa da periodicidade, a revista tem mais condições de ultrapassar os limites da informação, fazendo mais análises do fato, abordando todos os lados da notícia. Elas podem trabalhar com textos mais elaborados e criativos, usando recursos de estilo que normalmente não são possíveis no jornalismo diário, considerando a alta rotatividade do mesmo.

Para Scalzo (2011), o texto de revista semanal pode ser mais investigativo e interpretativo, não tanto objetivo quanto o texto do jornal diário. Por ser criativo, aproxima-se do estilo literário. E, de certa forma, a revista semanal de informações tem uma base narrativa que a faz ir além das informações sobre determinado acontecimento, com uso das reportagens em suas edições, ao contrário dos jornais diários.

Para Villas Boas (1996), o estilo de revista guarda suas especificidades, já que sua prática é de um jornalismo mais aprofundado, com informações mais detalhadas:

As revistas fazem jornalismo daquilo que ainda está em evidência nos noticiários, somando a estes pesquisa, documentação e riqueza textual. Isso possibilita a elaboração/produção de um texto prazeroso de ler, rompendo as amarras da padronização cotidiana. (VILLAS BOAS, 1996, p. 09)

Justifica-se assim o fato de os leitores, mesmo já tendo acompanhado a notícia nos veículos de comunicação imediatos, optarem pela revista, com 
documentos verbais e imagéticos característicos, a fim de reafirmar aquilo que já se conhece.

A revista preocupa-se também com o design, visando ao que ela deseja comunicar. Assim,

\begin{abstract}
Para conseguir transmitir e passar ideias do conteúdo é preciso manipular e equilibrar todos os componentes: mensagem, linguagem, imagens, tipografia, espaço, cor, sequência, contrastes, ordem e tudo o mais para orquestrá-los em um todo visualmente unificado e intelectualmente consistente. (ALI, 2009, p. 96)
\end{abstract}

Scalzo (2011, p. 58-59) ainda acrescenta que uma das vantagens da revista é o fato de elas possibilitarem inúmeros recursos gráficos como forma de complementar as informações tratadas no texto, seja com boas fotografias ou infográficos bem feitos. Assim, uma revista, em sua totalidade, precisa agrupar todos os elementos citados acima de forma harmoniosa para transmitir ao leitor sua composição e suas ideias.

\title{
4 JORNALISMO SENSACIONALISTA
}

De acordo com Angrimani Sobrinho (1995, p. 16), "sensacionalismo é tornar sensacional um fato jornalístico que, em outras circunstâncias editoriais, não merecia esse tratamento"). Portanto, o sensacionalismo é o aspecto exagerado que um meio de comunicação utiliza para noticiar, sem que a informação noticiada mereça tanta importância.

Para Silva e Paulino (2014), um jornal é sensacionalista em razão da necessidade de vender sempre mais e obter cada vez mais lucro. Para que se tenha expressivo número de leitores, muitos veículos utilizam o texto sensacionalista para noticiar.

Marcondes Filho (1988, apud PENA, 2010, p. 90), "a notícia é um produto à venda e está exposta na vitrine do capitalismo industrial [...] ela é a informação transformada em mercadoria com todos os seus apelos estéticos, emocionais e sensacionais".

Ainda citado por Pena (2010), Marcondes Filho (1988) afirma que a prática sensacionalista está diretamente ligada ao emocional; ela tira do fato a sua carga emotiva e apelativa e a potencializa, construindo uma nova notícia, capaz de se vender. O objetivo desta imprensa, independente do veículo de comunicação, não é informar, mas sim atender às necessidades de um público de uma sociedade espetacular. 


\subsection{A linguagem sensacionalista e seus pressupostos}

Apesar de o discurso sensacionalista ser reconhecido, na maioria das vezes, nos jornais destinados a atender a classes sociais menos favorecidas, como afirma Pedroso (2001), pode-se dizer que ele não é uma particularidade destes, uma vez que muitos outros veículos de comunicação considerados sérios fazem uso desse mesmo tipo de linguagem em determinadas situações, como aponta Angrimani Sobrinho (1995).

Para Pedroso (1983, apud ANGRIMANI SOBRINHO, 1995), o termo sensacionalista exclui um veículo de comunicação da classe dos jornais sérios. Porém, segundo Amaral (2006), é possível afirmar que todo jornal é sensacionalista, uma vez que se utiliza de elementos próprios para convencer e atrair leitores e, consequentemente, vender mais jornais.

Conforme Burnett (1967), nas palavras de Callado (2002), a ideia de informar envolve a notícia em uma linguagem clara, objetiva e concisa. De outra forma, quando há intenção de espetacularizar a notícia, valoriza-se a emoção em detrimento da informação, conforme indica Pedroso (2001).

Angrimani Sobrinho (1995) aponta uma característica sensacionalista de jornais e revistas: a inadequação entre manchete e texto, manchete e foto e também entre texto e foto. Para o autor,

[...] a manchete, dentro da estratégia de venda de uma publicação que adotou o gênero sensacionalista, adquire uma importância acentuada. A manchete deve provocar comoção, chocar, despertar a carga pulsional dos leitores. São elementos que nem sempre estão presentes na notícia e dependem da "criatividade" editorial. (ANGRIMANI SOBRINHO, 1995, p. 16)

Assim, o veículo de comunicação de viés sensacionalista tem a missão inicial de prender a atenção do leitor ou espectador pela manchete, mesmo que o teor desta não corresponda ao conteúdo noticiado.

A linguagem sensacionalista detém alguns pressupostos que a caracteriza. Pode-se dizer que estes garantem o interesse do leitor pela notícia, reforçando o conceito de Amaral (2006) em relação às vendas de jornais.

Silva e Paulino (2014) indicam a principal característica do sensacionalismo utilizada pelos meios de comunicação: o exagero. Conforme os autores, os temas dramáticos por si só já são uma tendência do jornalismo. Potencializar esses acontecimentos ao noticiá-los, explorando o que há neles de 
pavoroso ou grotesco, com apelos emotivos e sensoriais, é prática comum nas redações.

Para Pedroso (2003, p. 17), a emoção, a comoção e o choque são causas da dramaticidade que envolve a linguagem sensacionalista, isso ocorre ao enfatizar a emoção levando à comoção e não à informação, ao transformar notícia em espetáculo e, assim, reforçar a proximidade com o leitor.

Outra tendência da linguagem jornalística de caráter sensacional é a adjetivação, afirma Callado (2002). Um bom texto em jornal impresso não permite a adjetivação opinativa ou tendenciosa, pois sua característica principal é a simplicidade, a capacidade de fazer um texto completo e de comum entendimento aos leitores. Essa simplicidade, conforme afirma Burnett (1967, apud (ALLADO, 2002), vem da necessidade de se fazer um texto que atinja o maior número de pessoas.

Outra característica negativa da adjetivação é a depreciação. Para Chaparro (2013), muitas revistas utilizam textos na base da adjetivação agressiva, podendo esta ser até ofensiva, considerando sua política e ideologia editorial. $O$ autor afirma que a adjetivação depreciativa nada esclarece, mas sim deforma a estética narrativa de uma reportagem.

Além dos elementos supracitados correspondentes ao texto sensacionalista, Pedroso (2001) lista as principais características da prática sensacionalista na produção da notícia:

Intensificação, exagero e heterogeneidade gráfica; ambivalência linguístico-semântica que produz o efeito de informar através da não-identificação imediata da mensagem; valorização da emoção em detrimento da informação; exploração do extraordinário e vulgar, de forma espetacular e desproporcional; adequação discursiva ao status semiótico das classes populares; destaque de elementos insignificantes, ambíguos, supérfluos ou sugestivos; subtração de elementos importantes e acréscimo ou invenção de palavras ou fatos; valorização de conteúdos ou temáticas isoladas, com pouca possibilidade de desdobramento nas edições subsequentes e sem contextualização político-econômico-social-cultural; discursividade repetitiva, fechada ou centrada em si mesma, ambígua, motivada, impositiva, despolitizadora, fragmentária, unidirecional, vertical ambivalente, dissimulada, indefinida, substitutiva, deslizante, avaliativa, sedutora; exposição do oculto, mas próximo; produção discursiva sempre trágica, erótica, violenta, ridícula, insólita, grotesca ou fantástica; especificidade discursiva de jornal empresarial-capitalista pertencente ao segmento popular de grande empresa industrial-urbana, em busca de consolidação econômica no mercado jornalístico; escamoteamento da questão 
popular, apesar de pretenso engajamento com o universo social marginal; gramática discursiva fundamentada no desnivelamento sócio-econômico-cultural entre as classes hegemônicas e populares. (PEDROSO, 2001, p. 122-123)

Essas práticas citadas pela autora são evidenciadas em determinados acontecimentos noticiosos. Diante disso, Angrimani Sobrinho (1995, p.14) exemplifica, citando Mott (1941), que "o termo sensacionalismo poderá ser usado para o tratamento particular que um jornal dá a crimes, desastres, sexo, escândalos e monstruosidades", temas estes já caracterizados por uma carga emocional natural.

A ambivalência linguístico-semântica, citada por Pedroso (2001), produz o efeito de informar através da não identificação imediata da mensagem. Conforme a autora, isso ocorre em uma espécie de texto-apelo, principalmente em títulos e manchetes. Para a autora,

A construção dos títulos (em torno do jogo semântico-linguístico-tipográfico, visualizado na composição espacial do texto e valorizado pela ambivalência do significado ou do seu deslizamento) precisa que o efeito de reconhecimento erótico-chocante se imponha de imediato. Por isso, abre um espaço em branco em torno da palavra escolhida, principalmente daquela que o leitor-receptor desconhece. Isso contribui para envolve-la em um halo de indefinição, impregnando-a das mais diversas sugestões. Com essa poética da sedução, os títulos colocam-se intencionalmente abertos à livre fruição do leitor, no momento em que para em frente ao jornal exposto na banca e lê a sua manchete. (PEDROSO, 2001, p. 110)

Assim, a utilização desse pressuposto, na produção da notícia, garante ao meio o interesse do leitor por ela, de acordo com a curiosidade deste. Nas manchetes, a ambivalência é sugestiva ao leitor, conforme Pedroso (2001), fazendo uso de contribuições emotivas e imaginativas, permanecendo ambígua até a leitura do texto, quando diminui o seu efeito de indefinição ou de curiosidade. A autora acrescenta que os meios de comunicação que utilizam o discurso da sedução o fazem de forma que o leitor tenha outra percepção da notícia tratada dentro da reportagem. Trata-se de um joguete para seduzir o leitor e essa prática não condiz com as normas do jornalismo informativo. (PEDROSO, 2001, p. 111)

\section{METODOLOGIA}


Este artigo resulta de uma análise para compreensão dos limites entre informação e sensacionalismo na cobertura jornalística das revistas IstoÉ e Veja do incêndio na boate Kiss, observando o enfoque destas ao noticiarem esse acontecimento. Trata-se de uma pesquisa qualitativa, que permite comparações e interpretações. Segundo Minayo (2009), essa abordagem qualitativa envolve um universo de significados, motivos, aspirações, crenças, valores e atitudes, que não pretende dizer o que é certo ou errado, mas compreender a lógica que existe na prática da realidade.

A coleta de dados para a análise de conteúdo foi realizada nas edições das revistas: IstoÉ - Reportagem Especial, edição 2255, e Veja - Edição Especial, edição 2307. As duas edições foram veiculadas em 6 de fevereiro de 2013 e o material escolhido de ambas as revistas foram as capas e as reportagens informativas, sendo quatro reportagens da IstoÉ e sete da revista Veja.

A análise de conteúdo se deu a partir da identificação e da caracterização dos operadores analíticos e dos operadores conceituais, com a observação da proximidade dos operadores, objeto de análise, em relação ao jornalismo sensacionalista.

Os operadores analíticos título; lead²; narrativa; fotografia e recursos gráficos foram escolhidos considerando a importância destes dentro do conjunto que compõe a reportagem 3 .

Já os operadores conceituais Adjetivação e Dramaticidade foram escoIhidos tendo em vista que o jornalismo de qualidade não se deve pautar

2 "O lead é a abertura da matéria. Nos textos noticiosos, deve incluir, em duas ou três frases, as informações essenciais que transmitam ao leitor um resumo completo do fato. Precisa sempre responder às questões fundamentais do jornalismo: o que, quem, quando, onde, como e por quê" (MARTINS, 1997, p. 154)

3 Em uma reportagem ou capa de revista, o título precisa informar ao leitor aquilo que de mais importante será abordado ao longo da leitura do texto. O lead fará a abertura da reportagem, "deve incluir, em duas ou três frases, as informações essenciais que transmitam ao leitor um resumo completo do fato" (MARTINS, 1997, p. 154). Já a narrativa, conforme Scalzo (2011), precisa ter um texto diferenciado dos outros meios de comunicação, de forma clara e objetiva, trazendo novas informações a respeito do acontecimento. As fotografias têm função, além de informar, entreter e surpreender o leitor, ajudando a elucidar a notícia. Por fim, os recursos gráficos são utilizados na reportagem para informar ao leitor aquilo que o texto por si só não pode fazer. Por meio de tabelas, gráficos, desenhos ou mapas, eles ajudam a esclarecer o leitor, afirma a autora.

Texto curto utilizado na primeira página para chamar a atenção do leitor para a notícia de destaque. Disponível em: <http://jornalismo.ufma.br/thaisa/files/2012/03/gloss\%C3\%A1rio. pdf $>$. Acesso em: 22 nov. 2014. 
pelo excesso desses dois fatores, uma vez que eles vão contra as regras de objetividade e imparcialidade do jornalismo. Os operadores conceituais exagero gráfico, linguístico e semântico e ambivalência linguístico-semântica - foram definidos conforme Pedroso (2001).

As capas das revistas foram analisadas de forma diferenciada. Conforme Scalzo (2011), "uma boa revista precisa de uma capa que a ajude a conquistar leitores e os convença a levá-la para casa" (2011, p. 62). Dessa forma, considerando sua importância, as capas das duas edições selecionadas foram analisadas separadamente de acordo com os operadores analíticos: título, chamada ${ }^{4}$, fotografia e recursos gráficos e, também, em relação aos mesmos operadores conceituais.

\section{DESCRIÇÃO DO OBJETO E ANÁLISE DOS DADOS}

As revistas escolhidas para a análise, IstoÉ e Veja, são as principais revistas do mercado brasileiro e também as mais populares do país, conforme indica pesquisa do Instituto Verificador de Circulação - IVC, realizada em 2014. A Veja tem mais de um milhão de exemplares em circulação semanalmente, e a IstoÉ, uma média de 300 mil exemplares, conforme a mesma pesquisa.

A escolha desses veículos de comunicação como objeto desta pesquisa se deu em razão do alcance das duas revistas e da importância delas no mercado nacional, somados ao fato de que houve uma abordagem sistemática do acontecimento, dadas as edições especiais para a cobertura do incêndio da boate Kiss.

A edição de Veja enfoca o acontecimento em reportagens diferentes, cada uma com uma abordagem diferenciada. Já a edição de IstoÉ aborda um ou dois enfoques em apenas uma reportagem e, por isso, essas são em menor quantidade, sendo distribuídas em um número maior de páginas do que cada reportagem da revista Veja. No total, foram 11 reportagens e duas capas analisadas.

Para que haja clareza e melhor entendimento das análises, estas serão tratadas por "Capa" e "Reportagem", enumeradas conforme a ordem em

4 Texto curto utilizado na primeira página para chamar a atenção do leitor para a notícia de destaque. Disponível em: <http://jornalismo.ufma.br/thaisa/files/2012/o3/gloss\%C3\%A1rio.pdf>. Acesso em: 22 nov. 2014. 
que aparecem em cada revista, a saber: Revista IstoÉ - Reportagem Especial: Capa - Tolerância Zero, Reportagem I - A tolerância tem que ser zero, Reportagem II - As câmaras da morte, Reportagem III - Santa Maria, rogai por eles, Reportagem IV - O mesmo gás de Hitler. Revista Veja - Edição Especial: Capa - Nunca Mais, Reportagem I - Quando o Brasil vai aprender?, Reportagem II Os heróis de Santa Maria, Reportagem III - A asfixia não acabou, Reportagem IV - O apelo: "Preciso de ti", Reportagem V - Vida e morte nas redes sociais, Reportagem VI - A tênue fronteira entre o normal e o trágico, Reportagem VII - Preparados para o pior?.

O processo da análise se deu pela identificação e caracterização dos operadores analíticos que compreendem uma reportagem: título, lead, narrativa, fotografia e recursos gráficos e; dos operadores analíticos que compõem uma capa de revista: título, chamada, fotografia e recursos gráficos. Cada operador analítico, das capas e das reportagens, foi analisado conforme os operadores conceituais característicos do jornalismo sensacionalista, conforme Angrimani (1995) e Pedroso (2001): adjetivação, dramaticidade, exagero gráfico, linguístico e semântico e ambivalência linguístico-semântica (que produz o efeito de informar através da não-identificação imediata da mensagem).

\subsection{Adjetivação}

No geral, as duas revistas fazem uso recorrente da adjetivação, especialmente para descrever um sobrevivente, uma vítima fatal ou o incêndio, sem que comprometa a qualidade da narrativa, do lead ou do título. Em outras situações já é característico o excesso de adjetivação, o que torna penosa a leitura.

Considerando que um bom texto jornalístico é aquele de leitura e entendimento acessíveis ao maior número possível de leitores e, que, para isso, deve-se abrir mão do discurso tendencioso, Callado (2002) afirma que a simplicidade é a principal característica do texto em jornal impresso, que não permite a adjetivação opinativa ou tendenciosa.

Nesse sentido, percebe-se a presença da adjetivação, com intenção sensacionalista, na narrativa da Reportagem I de IstoÉ:

De tão evitável, essa tragédia parece sem sentido, pois ela é resultado da soma de todos os erros, os mais banais e inaceitáveis. É a prova de que as pequenas irregularidades viram grandes tragé- 
dias. Por mais chocante, absurdo e intolerável, o holocausto gaúcho tem de ser transformador. (ISTOÉ, fev. 2013, p. 42)

A adjetivação depreciativa ocorre nas duas revistas. Em suas narrativas há fragmentos de uma adjetivação agressiva e ofensiva ao utilizar as expressões: "fiscal corrupto", "falhas gritantes", "seguranças mal treinados e despreparados", "efeito nefasto", "macabro camarote” (ISTOÉ, fev. 2013, p. 42) e "empresários negligentes" (VEJA, fev. 2013, p. 61). Essas expressões, são características da intenção de direcionar a opinião do leitor para aquilo que a política editorial da revista deseja estimular.

\subsection{Dramaticidade}

A dramaticidade é o pressuposto do sensacionalismo mais presente nas reportagens e nas capas das duas revistas. Por se tratar de uma tragédia que resultou na morte de 242 jovens, naturalmente, possui uma carga emocional capaz de sensibilizar. $O$ incêndio e suas consequências comovem, chocam e indignam o leitor e, dessa forma, as duas revistas buscam envolvê-lo, potencializando ao máximo esses sentimentos.

As capas das duas revistas apresentam muitos indícios desse pressuposto. Elas utilizam o preto como cor predominante em sinal de luto. IstoÉ utiliza uma foto pequena ao centro que, mesmo não sendo de destaque, não minimiza o sentimento de dor que atinge o leitor. Na foto está uma mãe dependurada no caixão do primeiro filho, que estava sendo velado naquele dia. Ela perdeu seus dois filhos no incêndio e era amparada por um parente. Na chamada, os termos "estado de insegurança", "desprezo às leis e à vida" e "arapucas da morte" apelam para a reflexão do leitor a respeito de situação de perigo e descaso. No geral, a capa é simples e não tem muita informação. Apesar de a revista não tratar apenas da notícia do incêndio, toda a capa é destinada a ela. $O$ título e o nome da revista estão em letras garrafais e na cor branca, para fazer contraste com a única frase em vermelho: a data do incêndio. Já a revista Veja utiliza na capa um preto sombreado em volta de uma das imagens mais marcantes da tragédia, a namorada de uma vítima debruçada sobre o seu caixão com o rosto coberto pelo chapéu, modelo campeiro, dele. A imagem ocupa praticamente toda a capa da revista, que ainda usa a chamada e o título na cor branca, sendo que esse consta em letras garrafais as palavras: "Nunca mais". 
A chamada também é apelativa, pede por um país novo em memória de $235^{5}$ jovens mortos em Santa Maria e, ainda, cobra providências em relação ao descaso, à corrupção, à negligência e à impunidade do país, para que mais ninguém se torne vítima.

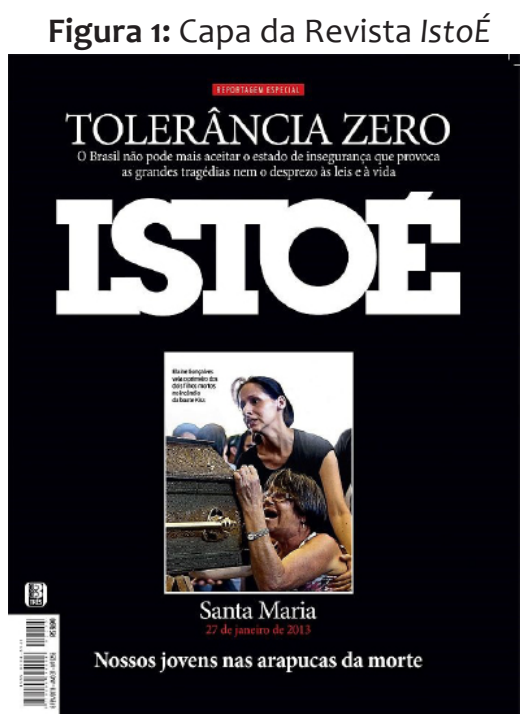

Fonte: IstoÉ, 2013.
Figura 2: Capa da revista Veja

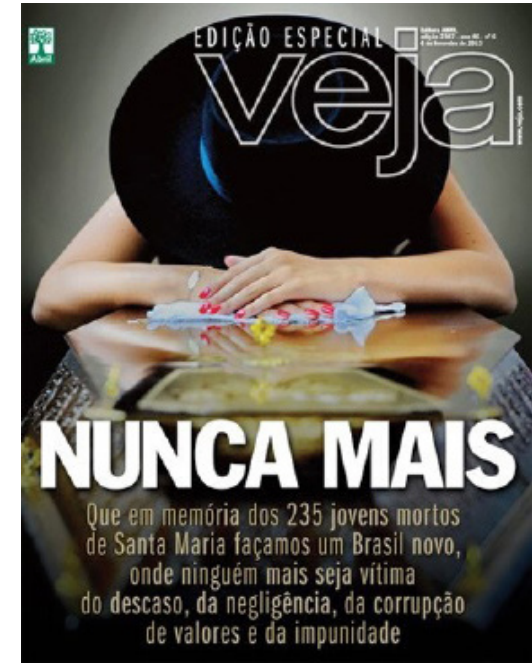

Fonte: Veja, 2013.

Os títulos, em particular, são marcados pelo teor dramático, ora em perguntas difíceis feitas ao leitor, ora no uso de expressões fortes, ora no uso do apelo de um sobrevivente. As Reportagens II, III, IV e V de IstoÉ exemplificam: "As câmaras da morte", "Santa Maria rogai por eles", "O mesmo gás de Hitler" e "Multidões, a grande ameaça". Em Veja, os títulos, todos em letras garrafais, das Reportagens I, II, III, IV e VII: "Quando o Brasil vai aprender?”, "Os Heróis de Santa Maria", “A asfixia não acabou", “O apelo: 'Preciso de ti"” e "Preparados para o pior?". Quando os títulos não estão diretamente relacionados ao acontecimento da tragédia, eles impõem ao leitor a participar dessa situação e poder se questionar - enquanto leitor - se: Eu estou preparado para o pior? Alguém se prepara para o pior? Ou, porque multidão é uma ameaça?

Conforme Pedroso (2003), a notícia de viés dramático, ao invés de informar, transforma a notícia em um show de espetáculo. Para a autora, os meios que utilizam essa característica distanciam o leitor do esclarecimento e de uma reflexão coerente sobre o acontecimento. Os leads e as narrativas,

5 Conforme a publicação da revista Veja, edição de seis de fevereiro de 2013, 235 jovens presentes na boate Kiss morreram no mesmo dia do incêndio. 
por diversas vezes, exercem essa função.

Em Veja, a Reportagem I inicia sua narrativa com um texto que tenta aflorar toda a indignação do leitor relacionando às vítimas da tragédia às irregularidades que motivaram o incêndio, como destacado no trecho abaixo:

Juliana Sperone Leniz, de 18 anos, foi condenada à morte em agosto do ano passado, quando expirou a licença de segurança contra incêndio da boate Kiss [...], e os bombeiros não apareceram para fazer a vistoria. (VEJA, fev. 2013, p. 58)

A narrativa segue fazendo essas relações, a informação no texto é que jovens foram mortos em decorrência de irregularidades que poderiam ser evitadas, mas a linguagem sedutora com a qual o texto foi elaborado é que dá o tom do excesso da dramaticidade. Além disso, nessa narrativa, observa-se a intenção da revista de condenar os acusados.

Por fim, os recursos gráficos aplicados às duas revistas abusam de teor dramático de sua composição. Na Reportagem II, o infográfico usa frases como: "Passo a passo da tragédia" e "Os bombeiros chegam ao local e já há gente morta a cerca de um metro da porta" (ISTOÉ, fev. 2013, p. 50). Na Reportagem I de Veja, o infográfico faz a reprodução de todo o acontecimento separando-os pelos subtítulos: "O rol da negligência", "Show de horrores" e, assim como em IstoÉ, o "Passo a passo da tragédia" (VEJA, fev. 2013, p. 59) e na Reportagem VI, com o subtítulo: "Os últimos minutos" (VEJA, fev. 2013, p. 75).

\subsection{Exagero gráfico, linguístico e semântico}

Conforme os autores Silva e Paulino (2014), a principal característica do discurso sensacionalista é o exagero e, em se tratando de notícias ruins, é fortemente utilizado para potencializar o que tem de mais chocante no acontecimento. Com as duas revistas analisadas não foi diferente: IstoÉ e Veja abusam das cores e das letras garrafais nos títulos, além de outros recursos, para destacarem o teor chocante das reportagens e chamarem a atenção dos leitores.

Na Reportagem IV de IstoÉ, há exagero com certa tendência ao sensacionalismo no título da matéria: "O mesmo gás de Hitler", que é fortemente exaltado ao permitir que o leitor entenda que foi utilizado o "gás de Hitler" para matar as vítimas. 
Em Veja, o exagero está impregnado na Reportagem II, há exagero na utilização de imagens após o incêndio. Foram produzidas fotos dos sobreviventes e de vítimas ainda hospitalizadas. Além disso, as fotos posadas em um cenário branco e vazio, das famílias das vítimas abraçadas, retratando a dor e o vazio daquele momento. Conforme exemplo abaixo, uma mãe abraça o chapéu do filho e em um quadro menor, mostra a foto do filho em um cavalo usando o mesmo chapéu.

Figura 3: Reportagem II da revista Veja

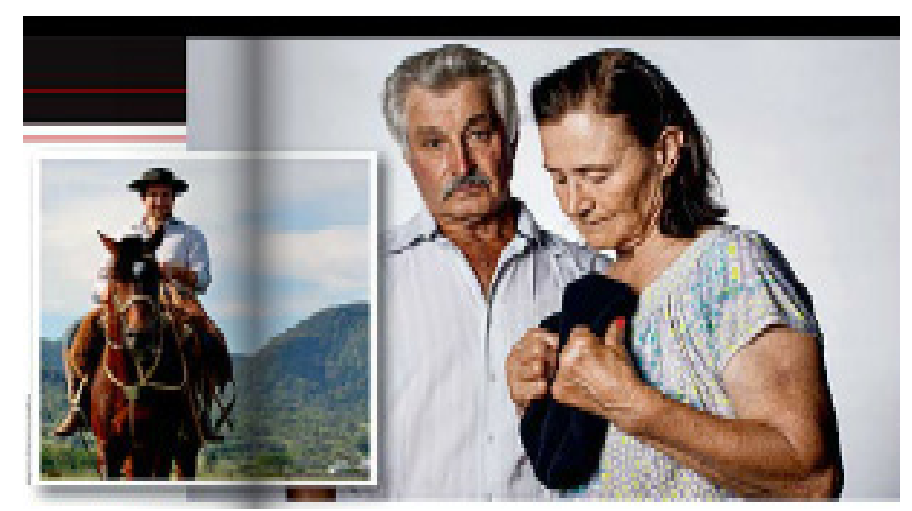

Fonte: Veja, 2013.

\subsection{Ambivalência linguístico-semântica}

Esse pressuposto parte da ideia de que a reportagem produz o efeito de informar, mas sem que haja identificação imediata da mensagem. Nesse sentido as duas revistas fazem uso desta característica do sensacionalismo em suas capas. Há ambivalência linguístico-semântica nos títulos das duas capas: IstoÉ, em primeiro plano, destaca o título: “Tolerância Zero" e, em segundo plano, o subtítulo: “Nossos jovens nas arapucas da morte”. Já Veja, coloca em letras garrafais o título: “Nunca Mais". Verifica-se que o título não é uma informação e sim uma manifestação, um apelo a respeito do que será abordado nas reportagens das revistas. No caso do subtítulo de IstoÉ, dá margem a várias outras interpretações daquilo que tratará a revista.

O título deve apresentar o acontecimento a ser noticiado ${ }^{6}$. Dessa forma, deve-se resumir em uma linha aquilo que a notícia tem de mais importan-

6 MARTINS, Eduardo. Manual de Redação e Estilo: O Estado de São Paulo. 3. ed. São Paulo, 1997. 
te e destacá-la no título para que o leitor determine se lerá a reportagem ou não. Os títulos da maioria das reportagens não cumprem essa função, apresentando a ambivalência linguístico-semântica produzindo o efeito de informar, porém sem a identificação imediata com a mensagem dentro da reportagem. Confere-se os casos das reportagens I, II, III e IV de IstoÉ e as reportagens I, III, V de Veja, destacando-se os títulos abaixo:

"As câmaras da morte" e "O mesmo gás de Hitler" permitem entender que a narrativa será a respeito das câmaras de gás da Segunda Guerra Mundial, porém, no decorrer da leitura, percebe-se que é feita apenas uma alusão com elas, comparando-as com a boate Kiss. E em "Santa Maria, rogai por eles", é feito novamente um apelo que não permite ao leitor entendimento imediato do que se trata o texto a seguir.

Com base nas análises dos operadores conceituais do sensacionalismo apresentadas anteriormente, pode-se inferir sobre a presença de características do jornalismo sensacionalista em meio à informação nas revistas IstoÉ e Veja.

\section{CONSIDERAÇÕES FINAIS}

A presente pesquisa buscou fazer uma reflexão a respeito do sensacionalismo apresentado pelas revistas nas coberturas realizadas, por meio dos elementos que compõem uma reportagem e uma capa de revista - narrativa, fotografia, títulos, lead's e demais recursos gráficos. Dessa forma, pode-se verificar evidências de que as duas revistas, IstoÉ e Veja, apresentaram em suas coberturas elementos característicos do jornalismo sensacionalista.

Considerando a importância do título dentro da reportagem, conclui-se que as duas revistas não contemplam sua função como se sugere. Um bom título exige criatividade, porém, foi pelo excesso de criatividade em alguns títulos de IstoÉ e Veja, que eles acabaram ficando confusos e dúbios. Esses títulos convencem o leitor a prosseguir com leitura da reportagem, porém a narrativa dela não cumpre aquilo que o título sugere ao leitor. $O$ que permite entendimento do contexto ao leitor, que o coloca no caminho certo da reportagem, são os leads. Na maioria das reportagens foi verificada a necessidade deles para dar sentido à notícia, porém, em outros casos, eles, muito sucintos, respondiam poucas das seis perguntas fundamentais do jor- 
nalismo ${ }^{7}$ que direcionam o repórter na produção de um lead.

As fotografias e recursos gráficos foram muito utilizados nas reportagens de IstoÉ e Veja. Há um provérbio chinês que diz que uma imagem vale mais do que mil palavras e, neste caso, as duas revistas souberam como aproveitá-las para potencializar a dramaticidade natural do acontecimento noticiado.

A narrativa por sua vez, é bem detalhada em Veja, que caracteriza minuciosamente as personagens de cada reportagem e, mais aprofundada em IstoÉ, que utiliza ganchos jornalísticos para aproveitar outros assuntos na mesma reportagem, não usando somente um caminho. Os textos, são fortemente caracterizados pela poética da sedução, um discurso que utiliza elementos específicos para envolver o leitor na reportagem. Nesse caso, o leitor é seduzido pela curiosidade em saber detalhes de um acontecimento trágico que envolveu a morte de centenas de pessoas.

Todos os operadores conceituais estudados estiveram presentes nas edições analisadas. A Adjetivação agressiva, ofensiva e que faz juízo de valor esteve presente em grande parte das narrativas e em alguns títulos de ambas revistas, porém, mais explícito em IstoÉ. Pode-se dizer que a Dramaticidade foi o operador conceitual mais presente em todas as edições, seja em fotos, infográficos, títulos, leads ou na narrativa. A Ambivalência linguístico-semântica foi a característica principal dos títulos das reportagens. No caso do operador conceitual Exagero, as revistas tentam prender a atenção do público. Esse operador é percebido na quantidade de imagens, nos títulos e nas narrativas que buscam garantir que o público faça a leitura até o final.

As Reportagens I de IstoÉ e Veja são as principais de cada revista. Elas trazem, em primeiro lugar, a informação do incêndio e de suas consequências. Porém, são também, as reportagens que mais apresentam indícios de sensacionalismo, principalmente nas narrativas, por meio de discurso adjetivado, dramático e exagerado.

Em relação às capas das revistas, as duas utilizaram imagens que retratam o pior momento da perda pela morte: a despedida. As fotos utilizadas para as capas são dos velórios de duas vítimas, onde ocorre a identificação e comoção do leitor pela perda de um filho, como apresentado em IstoÉ e

7 Segundo Erbolato (2006), em um Lead precisa-se responder, se possível, às seis perguntas fundamentais do jornalismo: Quem? Quê? Quando? Onde? Por quê? Como? 
pela perda do namorado, como apresentado em Veja. As capas das duas revistas utilizam discursos apelativos nos títulos e nas chamadas, mas ficou a cargo das fotografias elevarem toda a carga emocional do leitor.

Dessa forma, pode-se inferir que informação e sensacionalismo se misturaram na cobertura jornalística do incêndio na boate Kiss. $O$ acontecimento por si só já detém uma carga emocional muito forte que, conforme os vários critérios de noticiabilidade estudados já o caracterizam como um acontecimento noticioso. Porém, ao noticiá-lo, o que as duas revistas fizeram em suas coberturas foi potencializar todo esse sentimento natural do leitor, em um misto de sensibilização, comoção e indignação, através de sua linguagem. Além disso, pode-se concluir com este estudo que, de fato, a linguagem sensacionalista, conforme Pedroso (2001) e Angrimani Sobrinho (2005), não pode ser reconhecida apenas no jornalismo destinado às classes populares, IstoÉ e Veja não se enquadram nessas classes e fizeram uso de uma linguagem sensacionalista nas edições analisadas.

\section{REFERÊNCIAS}

ALI, Fátima. A Arte de Editar Revistas. 1. ed. São Paulo: Companhia Editora: Nacional, 2009. AMARAL, Márcia Franz. Jornalismo Popular. São Paulo: Contexto, 2006.

ANGRIMANI SOBRINHO, Danilo. Espreme Que Sai Sangue. Um estudo do sensacionalismo na imprensa. São Paulo: Summus, 1995.

BURNETT, Lago. A linguagem em (e não de) Jornal. In: Cadernos de Jornalismo, ano II, $n^{\circ} 6,1967$.

CALLADO, Ana Arruda. Deu no Jornal: O jornalismo impresso na era da internet. Disponível em: <http://books.google.com.br/books/about/deu_no_jornal.html?hl=ptB R\&id=yVUlwlpYKwQC $>$. Acesso em 22 Out. 2014.

CHAPARRO, Carlos. Porrete da Adjetivação Deforma Jornalismo. 05 de Março de 2013. Disponível em: <http://www.observatoriodaimprensa.com.br/news/view/_ed 736_porrete_da_adjetivacao_deforma_jornalismo>. Acesso em: 22 out. 2014.

ERBOLATO, Mário. Técnicas de Codificação em Jornalismo. 5. Ed. São Paulo: Ática, 2006. GALTUNG, J; RUGE, M. H. The Structure of Foreign News. Journal of International Peace Research, Vol. 1. No livro de Traquina, (1993).

G1. Disponível em: <http://g1.globo.com/rs/rio-grande-do-sul/noticia/2013/01/tragedia-em-santa-maria-o-que-ja-se-sabe-e-perguntas-responder.html>. Acesso em 18 nov. 2018.

MARCONDES FILHO, Ciro. O Capital da Notícia. São Paulo: Ática, 1988. . Televisão: a vida pelo vídeo. São Paulo, Moderna, 1988. 
MARTINS, Eduardo. Manual de Redação e Estilo: O Estado de São Paulo. 3. ed. São PauIo, 1997.

MINAYO, Maria Cecília de Souza (Org). Pesquisa Social: teoria, método e criatividade. 28. ed. Petrópolis: Vozes, 2009.

MOTT, Frank Luther: A History of Newspapers in the United Stales Through 250 Years. Estados Unidos, Macmillan, 1941.

PEDROSO, Rosa Nívea. A Construção do Discurso de Sedução em um Jornal Sensacionalista. São Paulo: Annablume, 2001

. A Produção do Discurso de Informação num Jornal Sensacionalista. Rio de Janeiro, UFRJ/Escola de Comunicação, 1983.

. Elementos para compreender o jornalismo informativo. Janeiro de 2003.

Disponível em: <http://www.crisluc.arq.br/ elementos\%20para\%20 compreender $\% 200 \% 20$ jornalismo\%2oinformativo.pdf>. Acesso em: 10 out. 2014.

Publiabril. Disponível em: <http://www.publiabril.com.br>. Acesso em: 17 out. 2014.

PENA, Felipe. Teoria do Jornalismo. 3. ed. São Paulo: Contexto, 2010 - 2012.

REVISTA ISTOÉ. Reportagem Especial. São Paulo: Editora 3, edição 2255, fev. 2013.

REVISTA VEJA. Edição Especial. São Paulo: Editora Abril: Edição Especial, edição 2307 fev. 2013.

SCALZO, Marília. Jornalismo de Revista. 4. ed. São Paulo: Contexto, 2011.

SILVA, Luiz Martins da; PAULINO, Fernando Oliveira. Jornalismo de Centavos, Sensacionalismo e Cidadania. 29 de Abril de 2014. Disponível em: <http:// www.observatóriodaimprensa.com.br/news/view/_ed796_jornalismo_de_centavos_sensacionalismo_e_cidadania>. Acesso em: 01 set. 2014.

TRAQUINA, Nelson. Teorias do Jornalismo: Porque as notícias são como são. Vol. 1. 2. ed. Florianópolis: Insular, 2005.

- Teorias do Jornalismo: A tribo jornalística - uma comunidade interpretativa

transnacional. Vol. 2. 1. ed. Florianópolis: Insular, 2005.

WOLF, Mauro. Teorias da Comunicação. 8. ed. Lisboa: Editorial Presença, 2003. 


\section{Cláudia de Oliveira Mendes}

Graduada em Comunicação Social - Jornalismo pela Faculdade Pitágoras de Belo Horizonte e graduanda em Ciências Sociais pela Universidade Federal de Minas Gerais (UFMG). Atualmente é revisora da Revista Em Debate e das mídias sociais do Grupo Opinião Pública da UFMG.

E-mail: claudiamendes2@live.com

\section{Luciana Amormino}

Doutoranda e Mestre em Comunicação Social pela Universidade Federal de Minas Gerais (UFMG). Graduada em Comunicação Social - Jornalismo pela Pontifíca Universidade Católica de Minas Gerais (PUC Minas). É professora de cursos de graduação em Comunicação Social e pós-graduação em Gestão Cultural do Centro Universitário UNA.

E-mail: luarmormino@gmail.com 